\title{
Parents' Opinions and Knowledge About Vaccination in Poland - A Cross-Sectional Observational Study
}

\author{
Paulina Pisaniak (D) \\ Aleksander Tarczon (D) \\ Milena Konarska $\mathbb{( D}^{2}$ \\ Dorota Ozga (iD ${ }^{3}$
}

'Emergency Medical Services Scientific Circle, Faculty of Medicine, University of Rzeszów, Rzeszów, Poland; ${ }^{2}$ Department of Pathophysiology, Jessenius Faculty of Medicine in Martin, Comenius University in Bratislava, Bratislava, Slovakia; ${ }^{3}$ College of Medical Sciences, Institute of Health Sciences, University of Rzeszow, Rzeszow, Poland
Correspondence: Dorota Ozga

Tel +48575 78I 979

Email gdozga@poczta.fm
Background and Objectives: Despite the fact that vaccines save many lives worldwide, in many countries, including Poland, the percentage of unvaccinated children is constantly growing. The main reasons for low immunisation coverage include parents' concerns about the safety of vaccines, their fears related to possible adverse events following vaccination, and the increasingly powerful activity of anti-vaccine movements. It is necessary to monitor the public's attitudes to vaccination in order to implement appropriate solutions to prevent a resurgence of epidemics. The aim of the study was to assess Polish parents' opinions about and awareness of immunisation-related issues.

Methods: The study, based on an online survey, investigated Polish mothers' attitudes towards the use of vaccines, their opinions regarding the sanctions for a failure to vaccinate a child, and the correlations between the result and the socio-demographic characteristics.

Results: A total of 646 responses were collected, including 593 from mothers from generalinterest groups and 53 from anti-vax groups. Differences were identified in vaccination coverage among children of respondents from general-interest groups and anti-vax groups. The findings show that the respondents from anti-vax groups stopped vaccinating more often due to vaccine adverse events and inadequate response from doctors.

Conclusion: Most of the respondents are aware of anti-vaccine movements and have a negative attitude to them, but these movements still influence the public. Also, the findings show a correlation between the level of education and a general attitude to immunisation people with higher education more often have a negative opinion on this matter.

Keywords: immunisation, social media, vaccine adverse events, anti-vaccine movement

\section{Introduction}

In Poland parents' confidence in vaccines has been eroding for many years, ${ }^{1}$ which is associated with the emergence and increasing popularity of anti-vaccine movements, ${ }^{2}$ and with the fact that more and more parents use the social media to find information about the related issues. However, research has shown that those who rely on opinions encountered in the social media are more likely to be misled than people who acquire information for instance from the traditional mass media. ${ }^{3,4}$ Vaccine hesitancy among parents may also be promoted by the lack of consistency in the information provided by healthcare professionals. ${ }^{5}$ Hadjipanayisa et al reported that parents who consulted with paediatricians or nurses showed lower vaccine hesitancy compared to parents who asked family doctors for the related advice. ${ }^{6}$ Studies show that pediatricians who talk to parents in a way that 
suggests vaccination (rather than asking their opinion about the vaccine) during a child's follow-up visit gain a higher percentage of parents who immediately express confidence and willingness to vaccinate their child. ${ }^{7}$ On the other hand, the study conducted by Zarobkiewicz et al shows that the knowledge related to vaccines among medical students is insufficient ${ }^{8}$ and it is necessary to take effort in order to change this adverse situation so that in the future, when they start working as medical professionals, they can effectively address parents' doubts and present reliable information consistent with the current state of medical knowledge. However, refusing to vaccinate their children can also be a problem for parents who are nevertheless in favor of vaccination. In a study by Wang et al, two most important reasons for this were identified. First, there is frustration about the information that often overwhelms parents with different views on the vaccine. Second, parents may have a dilemma between the "scientific" and "unscientific" approach to this matter. These two reasons were often associated with a delay in the vaccination schedule. ${ }^{9}$ Operations aimed to ensure regular monitoring of the public's confidence and opinions related to vaccines, and to improve our understanding of the most common concerns or doubts, as well as analyses of vaccination coverage in specific populations will make it possible to quickly identify the causes for the negative attitudes and to initiate interventions to prevent deterioration of population immunity and to avoid risks of epidemics.

\section{Materials and Methods}

The study applied a specially designed questionnaire. It was posted in an electronic format on a social networking site, in general-interest groups designed for and followed by mothers, and in groups focusing specifically on vaccination, and related to anti-vaccine movements. The questionnaire consisted of 24 questions. It was divided into four main parts: the demographic characteristics of the responding mothers; questions related to immunisation attitudes and behaviours; questions differentiating the respondents' awareness of vaccines, their activity, specification and the possible vaccine reactions; as well as questions related to sanctions imposed on parents who fail to vaccinate their children. The questionnaire's structure consisted of single-choice questions, multiple-choice questions, open questions. The questionnaire was distributed online, with the authors posting it through Facebook groups. General groups were searched for using the following keywords: child, motherhood, parents, pregnancy, childbirth, upbringing and other related and other related to the topic of children. Antivaccine groups were selected by meticulously following the fasting and general mood of the group members. The method of selecting and choosing social media groups is described above. The responses from the two types of groups were analysed separately. The population investigated consisted of Polish residents, mothers of children below 18 years of age. Responses to the survey were submitted by 646 women. The sample size was calculated on the basis of the number of women of reproductive age in Poland, with a confidence level of $95 \%$. The survey was conducted in the period from 12 Feb. 2020 to 26 Feb. 2020.

\section{Ethical Considerations}

Dissemination of the questionnaire in appropriate groups was preceded by the approval of the questionnaire by the administrator of a given group. Participation in the study was completely voluntary and anonymous. The respondents were instructed about the scientific nature of the study. Each participant could stop completing the questionnaire at any stage, and the respondent's informed consent to participate in the study was the sending of a completed questionnaire by the respondent. The study was conducted in accordance with the Helsinki declaration. Participation in the study of people under the age of 18 was reviewed and approved by the University of Rzeszow (No. 5/9/2017). Participants under the age of 18 years were approved by the ethics committee to provide informed consent on their own behalf.

\section{Results}

\section{Characteristics of the Study Group}

Women aged 15-65 years took part in the study. One in two respondents was aged between 27 and 35 years. Rural area was reported as a place of residence by $25.54 \%$ of the respondents. Urban areas with populations up to 50,000, up to 250,000 and over 250,000 were reported as a place of residence by $23.07 \%, 26.78 \%$ and $24.61 \%$ respondents, respectively. More than half of the respondents, ie, $63.31 \%$ reported higher education level. Approximately one in three respondents, ie, $30.03 \%$, reported secondary education level. Vocational education was reported by $4.33 \%$ while primary education was reported by $2.32 \%$ of the respondents [Table 1]. 
Table I Demographic Characteristics of Study Participants by Attitudes Toward Vaccination

\begin{tabular}{|c|c|c|c|}
\hline & $\begin{array}{l}\text { General } \\
\text { Groups }\end{array}$ & $\begin{array}{l}\text { Anti- } \\
\text { Vaccine } \\
\text { Groups }\end{array}$ & $\begin{array}{c}\text { In } \\
\text { General }\end{array}$ \\
\hline $\begin{array}{l}\text { Geographical distribution } \\
\text { of respondents }\end{array}$ & $91,80 \%$ & $8,20 \%$ & $100 \%$ \\
\hline Average age & 30,8 & 31,87 & 30,89 \\
\hline \multicolumn{4}{|l|}{ Place of residence } \\
\hline Village residents & $25,13 \%$ & $30,19 \%$ & $25,54 \%$ \\
\hline $\begin{array}{l}\text { Respondents live in cities } \\
\text { with a population of up to } \\
50,000\end{array}$ & $23,10 \%$ & $22,64 \%$ & $23,07 \%$ \\
\hline $\begin{array}{l}\text { Respondents live in cities } \\
\text { with a population between } \\
50,000 \text { and } 250.000\end{array}$ & $26,64 \%$ & $28,30 \%$ & $26,78 \%$ \\
\hline $\begin{array}{l}\text { Residents of cities with } \\
\text { a population of at least } \\
250,000\end{array}$ & $25,13 \%$ & $18,87 \%$ & $24,61 \%$ \\
\hline \multicolumn{4}{|l|}{ Education } \\
\hline Higher & $63,24 \%$ & $64,15 \%$ & $63,31 \%$ \\
\hline Secondary & $30,19 \%$ & $30,19 \%$ & $30,19 \%$ \\
\hline Vocational & $3,88 \%$ & $5,66 \%$ & $4,02 \%$ \\
\hline Primary & $2,70 \%$ & $0,00 \%$ & $2,48 \%$ \\
\hline
\end{tabular}

\section{Practices Related to Vaccination of Children}

Majority of the survey participants, ie, $82.35 \%$, vaccinate their children, while $17.65 \%$ of the respondents reported they did not do that. Out of all the survey participants, $8 \%$ represented groups promoting anti-vaccine movements - in this group two in three respondents $(66.03 \%)$ asserted they did not vaccinate their children, while $33.97 \%$ declared they did.

Majority of those who did not vaccinate their children (76.32\%) were concerned about a risk of complications and adverse vaccine reactions. Approximately one in four respondents do not believe that vaccines are effective (25.44\%). The opinion that getting over a disease is better than a vaccine as it leads to longer lasting immunisation was also supported by nearly one in four respondents (24.56\%). A group comprising $11.4 \%$ of the respondents maintained they did not vaccinate their children for health reasons. Approximately one in five respondents $(21.93 \%)$ who do not vaccinate their children had their own opinion related to this issue [Table 2].

Among the respondents representing general-interest groups, $86.68 \%$ reported they had vaccinated their children, while $13.32 \%$ selected the option saying they had not
Table 2 The Reasons Why the Respondents Refuse to Vaccinate Their Children

\begin{tabular}{|l|c|c|}
\hline $\begin{array}{l}\text { What is the reason for your decision not to } \\
\text { vaccinate your child? }\end{array}$ & $\mathrm{N}=\mathrm{II} 4$ & $\%$ \\
\hline Risk of post-vaccination complications & 87 & $76,32 \%$ \\
\hline In my opinion, vaccines are ineffective & 29 & $25,44 \%$ \\
\hline $\begin{array}{l}\text { In my opinion disease is better than vaccination } \\
\text { and gives longer-lasting immunity }\end{array}$ & 28 & $24,56 \%$ \\
\hline $\begin{array}{l}\text { My child has not been vaccinated for health } \\
\text { reasons }\end{array}$ & 13 & $11,40 \%$ \\
\hline Other & 25 & $21,93 \%$ \\
\hline
\end{tabular}

vaccinated their children. However, further analysis of the responses provided by the latter showed that some of them had started the immunisation program but then they decided to discontinue it for various reasons [Figure 1]. The most common reasons included incidence of adverse vaccine reactions resulting in fear of the subsequent vaccinations, or postponement of vaccination for health reasons.

Among the survey participants representing anti-vax groups, and constituting $8 \%$ of the population studied, $33.97 \%$ of the respondents declared their children had been vaccinated, while $66.03 \%$ reported they had not vaccinated their children. In the latter group approximately one in three respondents had started the immunisation program and then discontinued it for various reasons while two in three respondents had not vaccinated their children at all [Figure 2].

\section{Awareness Related to Immunisation}

In the study group, $69.04 \%$ of the respondents believed that SERIOUS adverse vaccine reactions occurred rarely (1:1000 000), $19.04 \%$ of the respondents thought these occurred frequently $(1: 10,000)$, and $11.92 \%$ maintained these were very common (1:100). The groups of respondents vaccinating their children and those refusing to do so differed significantly in these opinions $\left(\chi^{2}=297.47, \mathrm{p}<0.00001\right)$. The respondents who did not vaccinate their children were significantly more often convinced about frequent occurrence of serious undesirable reactions to vaccines.

\section{Popularity and Impact of Anti-Vaccine Movements}

The survey showed that anti-vaccine movements were known to $74.40 \%$ and unknown to $22.60 \%$ of the 


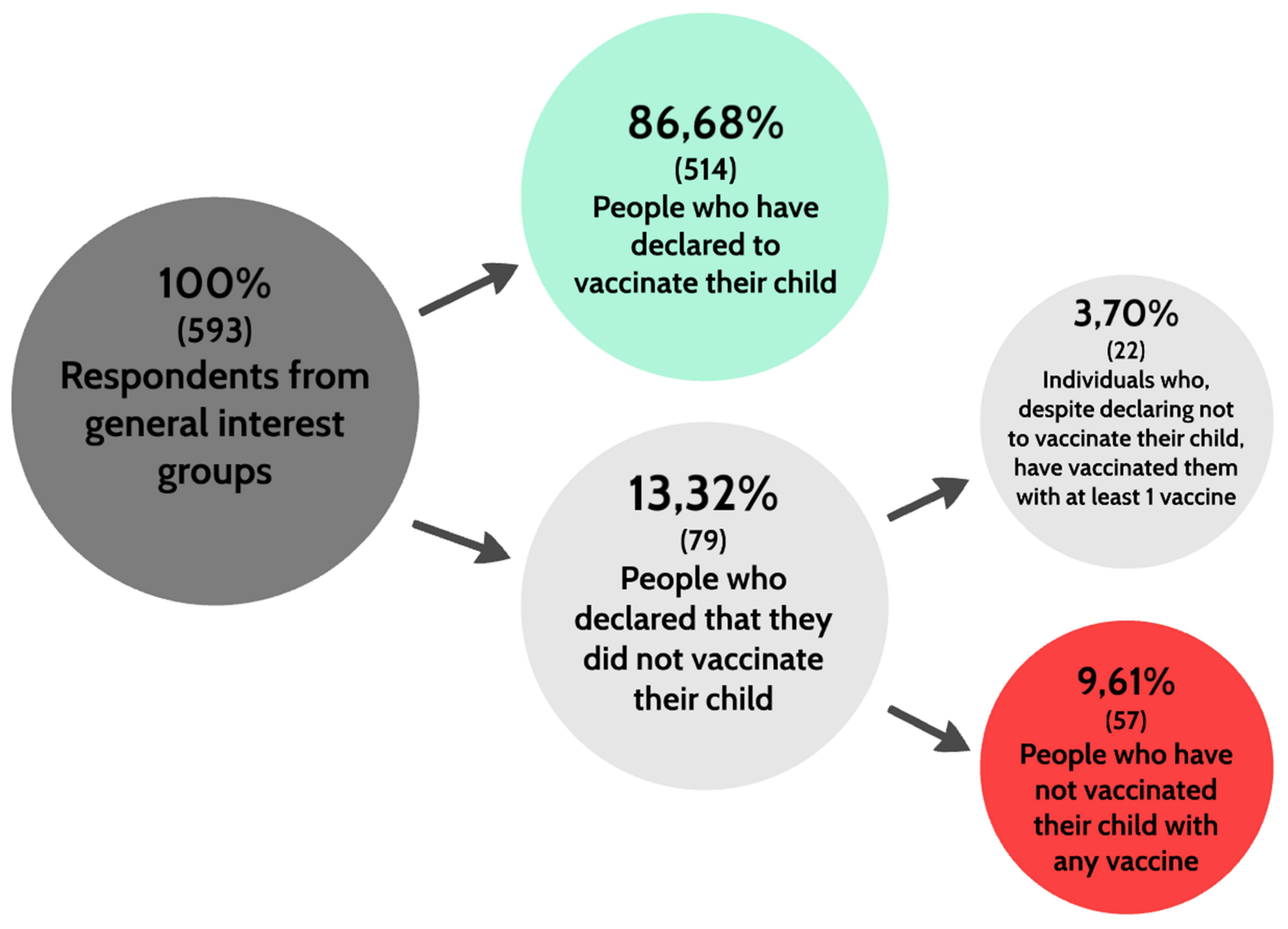

Figure I Analysis of the practices related to vaccination of children by the respondents from general-interest groups.

respondents. In the group of those familiar with anti-vaccine movements, $51 \%$ reported negative opinion about activities of such movements, $17.8 \%$ reported positive opinion and $31.20 \%$ had no opinion related to this issue. In the group of survey participants familiar with anti-vaccine movements the distribution of the opinions in the groups of respondents vaccinating or not vaccinating their children was significantly different $\left(\chi^{2}=192.54, \mathrm{p}<0.00001\right)$. The latter respondents significantly more often had positive opinions about activities of anti-vaccine movements.

As many as $64.86 \%$ of the survey participants reported that someone had tried to convince them about harmful effects of vaccines, while $35.14 \%$ of the respondents maintained that nobody had ever attempted to do so. The distribution of the opinions in the groups of respondents vaccinating or not vaccinating their children was significantly different $\left(\chi^{2}=67.92, p<0.00001\right)$. In the group of those who do not vaccinate their children significantly fewer respondents reported that someone at some point tried to convince them about harmfulness of immunisation.

\section{Characteristics of Vaccines Used}

The survey showed that $66.35 \%$ of the parents immunising their children $(n=532)$ used combination vaccines while $33.65 \%$ did not use such vaccines. In the group of those who did not use this type of immunisation, $50 \%$ believed that combination vaccines are more risky, compared to traditional vaccines; $29.4 \%$ did not use this option for financial reasons, $4.2 \%$ of the respondents were not aware of this options, while $17.40 \%$ of the respondents reported other reasons. More than half of the respondents (59.59\%) immunising their children $(\mathrm{n}=532)$ used additional (recommended) vaccines where payment is required, $40.41 \%$ did not use such vaccines. Majority of the respondents $(66.41 \%)$ maintained they would use the recommended vaccines if these were free of charge. As many as $33.59 \%$ of the respondents admitted they would not use the additional (recommended) vaccines even if they were free of charge. The distribution of the opinions in the groups of respondents vaccinating or not vaccinating their children was significantly different $\left(\chi^{2}=301.80\right.$, 


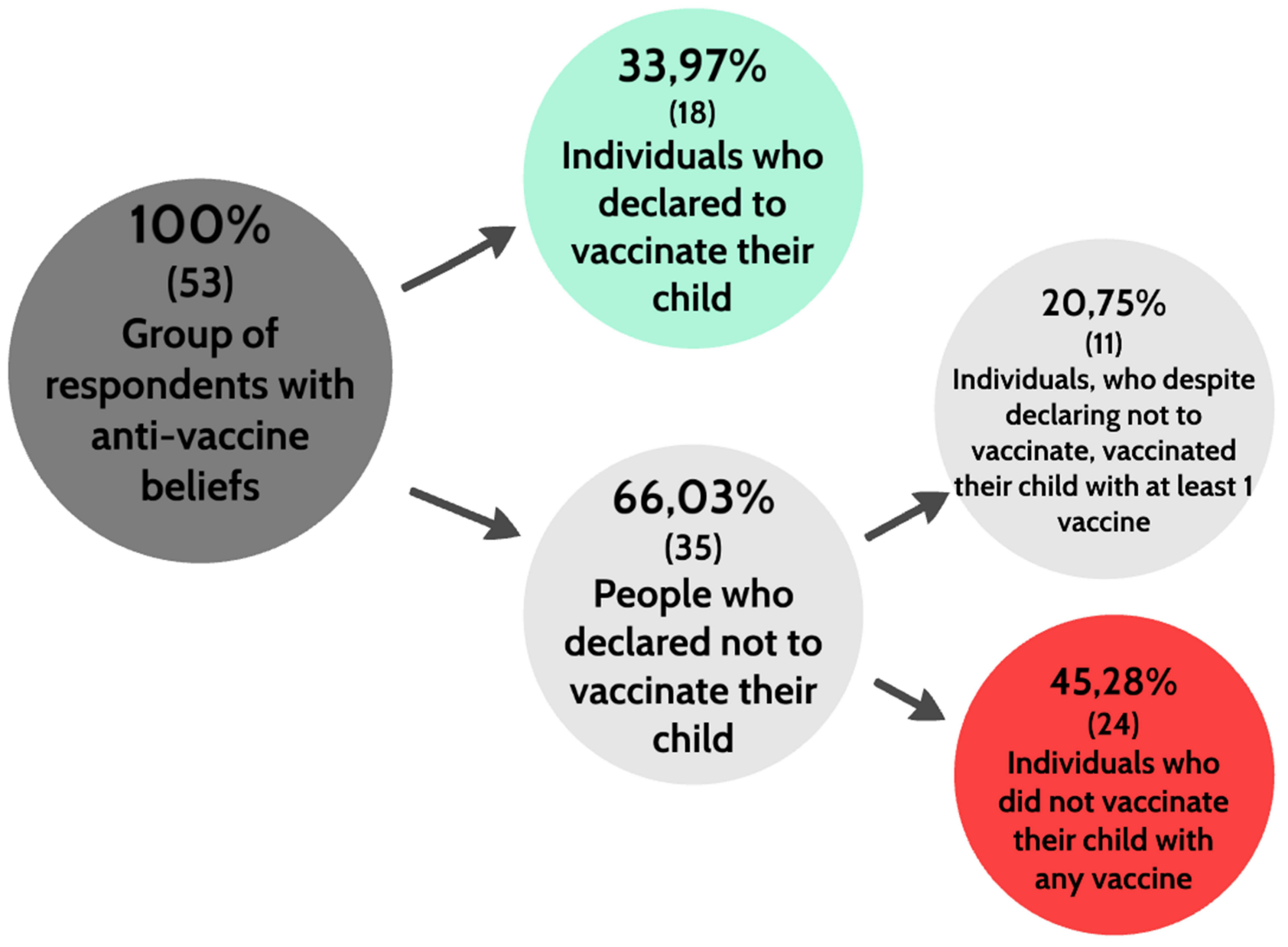

Figure 2 Analysis of the practices related to vaccination of children by the respondents from anti-vaccine groups.

$\mathrm{p}<0.00001$ ). The respondents refusing to immunise their children generally would not choose to use the vaccines, even if they were free of charge.

\section{The Use of Sanctions Against Parents Refusing to Immunise Their Children}

The survey showed that $67.18 \%$ of the respondents were in favour of the measures restricting access to nurseries and kindergartens for unvaccinated children; $24.61 \%$ of the respondents did not agree that such measures were justified; no opinion related to the matter or a different opinion was reported by $4.80 \%$ and $3.4 \%$ of the survey participants, respectively. The distribution of the opinions in the groups of respondents vaccinating or not vaccinating their children was significantly different $\left(\chi^{2}=377.3, p<0.00001\right)$. The respondents refusing to immunise their children far more frequently disagree with the statement that restrictions should be imposed on unvaccinated children's access to nurseries and kindergartens. When they were asked about financial penalties imposed for a failure to immunise one's child, $52.48 \%$ of the respondents agreed this was an appropriate measure, while $24.61 \%$ of the respondents thought it was not fair, and $16.41 \%$ did not have an opinion on that matter. The distribution of the opinions in the groups of respondents vaccinating or not vaccinating their children was significantly different $\left(\chi^{2}=284.27\right.$, $\mathrm{p}<0.00001)$. Great majority of the respondents refusing to immunise their children are against financial penalties for a failure to vaccinate the child [Table 3].

\section{Discussion}

In the process of the analysis of the responses to the question about immunization of the child, the group of respondents was divided according to their views on vaccination. The first group consisted of members of generalinterest groups [Figure 1], and the second group comprised members of anti-vaccine groups [Figure 2]. The most 
Table 3 Approaches to the Topic of Vaccination by Attitude

\begin{tabular}{|c|c|c|c|}
\hline & General Groups & Anti-Vaccine Groups & In Genera \\
\hline \multicolumn{4}{|l|}{$\begin{array}{l}\text { Do you have your child/children } \\
\text { vaccinated? }\end{array}$} \\
\hline Yes & $86,68 \%$ & $33,97 \%$ & $82,35 \%$ \\
\hline No & $13,32 \%$ & $66,03 \%$ & $17,65 \%$ \\
\hline \multicolumn{4}{|c|}{$\begin{array}{l}\text { Are you familiar with anti-vaccine } \\
\text { movements? }\end{array}$} \\
\hline Yes & $77,23 \%$ & $79,25 \%$ & $77,40 \%$ \\
\hline No & $22,77 \%$ & $20,75 \%$ & $22,60 \%$ \\
\hline \multicolumn{4}{|c|}{$\begin{array}{l}\text { How do you assess anti-vaccination } \\
\text { movements' activity? }\end{array}$} \\
\hline Unsatisfactory & $53,49 \%$ & $23,81 \%$ & $51,00 \%$ \\
\hline Neutral & $31,66 \%$ & $26,19 \%$ & $31,20 \%$ \\
\hline Satisfactory & $14,85 \%$ & $50,00 \%$ & $17,80 \%$ \\
\hline \multicolumn{4}{|c|}{$\begin{array}{l}\text { Has anyone ever tried to convince you of } \\
\text { the harmfulness of vaccination? }\end{array}$} \\
\hline Yes & $66,10 \%$ & $50,94 \%$ & $64,86 \%$ \\
\hline No & $33,90 \%$ & $49,06 \%$ & $35,14 \%$ \\
\hline \multicolumn{4}{|c|}{$\begin{array}{l}\text { What is the average frequency in your } \\
\text { opinion of SERIOUS adverse vaccine } \\
\text { reactions? }\end{array}$} \\
\hline I:I000 000 (rarely) & $73 \%$ & $23 \%$ & $69 \%$ \\
\hline $\mathrm{I}: 10,000$ (often) & $17 \%$ & $38 \%$ & $19 \%$ \\
\hline I: 100 (very often) & $10 \%$ & $39 \%$ & $12 \%$ \\
\hline \multicolumn{4}{|c|}{$\begin{array}{l}\text { Do you think that it is right to impose } \\
\text { financial penalties on parents for not } \\
\text { having a child vaccinated? }\end{array}$} \\
\hline Yes & $55,48 \%$ & $18,87 \%$ & $52,48 \%$ \\
\hline No & $27,49 \%$ & $71,70 \%$ & $31,11 \%$ \\
\hline Depends on the circumstances & $17,03 \%$ & $9,43 \%$ & $16,41 \%$ \\
\hline \multicolumn{4}{|c|}{$\begin{array}{l}\text { Do you think that it is right to limit access } \\
\text { to nurseries and kindergartens for } \\
\text { unvaccinated children? }\end{array}$} \\
\hline Yes & $55,5 \%$ & $18,9 \%$ & $52,5 \%$ \\
\hline No & $27,5 \%$ & $71,7 \%$ & $24,61 \%$ \\
\hline I do not know & $17,0 \%$ & $9,4 \%$ & $8,21 \%$ \\
\hline
\end{tabular}

common reasons why preventive vaccination program was discontinued included incidence of serious vaccine reaction in the child, belief that the vaccines are toxic, and belief that there is no reliable information about the composition of the vaccines, despite the fact that information about composition of vaccines is generally available, eg, on the website of the Office for Registration of Medical Products, Medical Devices and Biocidal Products (under Register of Medical Products) or on the website of the European Medicines Agency (in the browser one needs to enter the commercial name of the vaccine and the phrase Characteristics of Medical Product). ${ }^{10}$ The individuals supporting anti-vaccine trends far more frequently than the parents from general-interest groups responded they refused to immunise their children, which is consistent with their general attitude to this issue. Notably, these individuals over four times as often as the respondents from general-interest groups discontinued preventive vaccination of their children due to an undesirable incident, most frequently an adverse vaccine reaction (AVR). These 
parents commonly reported that after their child developed an AVR, the problem was not adequately addressed by healthcare personnel, and no help or recommendations for further treatment were provided to them. This may be a direct cause for the parents' lack of confidence in immunisation and a radical change in their approach to this type of preventive measure.

Analysis of the responses to questions selectively checking the level of awareness in the survey participants showed that the individuals representing general-interest groups far more often provided correct responses to the question related to the incidence of serious AVRs according to $73.19 \%$ of these respondents such reactions occur approximately in one case per million, which is a correct answer. ${ }^{11}$ On the other hand, in the group of antivaxxers only $22.64 \%$ selected the correct answer, while $37.74 \%$ responded that such reactions occur in one case per 10,000 vaccines administered. The latter rate in fact corresponds to the incidence of mild AVRs; therefore, it can be assumed that these individuals lack sufficient knowledge of potential post-vaccine complications, which indeed may occur just like other complications resulting from medical procedures and constituting an inherent part of the risk linked with any medical interventions. Most respondents (39.62\%) from anti-vax groups maintained that serious AVRs are very common and occur in one case per 100 vaccines administered. According to official data, ${ }^{11}$ this is the frequency of local and temporary symptoms, such as pain and redness at the injection site, as well as fever, and fussiness of the child and they are not classified as serious AVRs. Nearly three in four respondents $(74.40 \%)$ in the whole group of survey participants were aware of the activities of anti-vaccine movements. Along with the progress and expansion of this type of movement, Polish people's confidence in immunisation may decrease, although the related rates today are among the lowest in Europe. ${ }^{6}$ Anti-vaccine movements make use of a few psychological mechanisms taking advantage of personality types, to magnify parents' anxiety. ${ }^{12}$ They employ simple methods which make it possible to easily reach the public and to gain followers. Nearly $70 \%$ of the survey participants who have good opinion of anti-vaccine movements refuse to immunise their children, which suggests that vast majority of individuals supporting these activities indeed follow their recommendations.

The current findings show that significant majority of parents, ie, $67.18 \%$ would not want their children to attend care and educational facilities with children who were not immunised without valid medical reasons. Some parents maintained that this restriction is appropriate; however, it should not apply to children who are not vaccinated for health reasons. Some survey participants believed that implementation of such restrictions would mainly punish the children; some respondents insisted that unvaccinated children do not pose threat to the vaccinated peers, because the latter have been artificially immunised. This in fact is a misconception, because according to Robert Wagner, an activist from Wrocław, and a co-author of the Civic Legislative Initiative "We vaccinate because we think" - "If three children in a group of twenty are not vaccinated - it is enough to go below the threshold of protection against diseases" ${ }^{13}$ One can also encounter opinions that such mandatory requirements violate the Polish constitution; however, many experts argue that it is human well-being and public safety which according to the Constitution are most important. ${ }^{14}$ Hence, such opinions may result from the lack of awareness and ignorance presented by parents. ${ }^{15}$

\section{Conclusions}

The current findings show that majority of Polish mothers are confident that protective vaccination is important. The study has also identified a lack of trust in some parents, related both to the procedure of immunisation and to healthcare professionals who do not provide exhaustive answers to questions asked by parents, and who do not show sufficient interest in the small patients affected by vaccine-related complications. This frequently discourages parents from coming back for subsequent vaccinations, and increases their anxiety. Additionally, activity of more and more numerous anti-vaccine movements may adversely affect parents' confidence in immunisation, and contribute to decreasing vaccination coverage in the population while increasing a risk of resurgence of preventable diseases and epidemics. Therefore, it is necessary to regularly assess parents' awareness, opinions, anxieties and beliefs in order to respond to the changing attitudes, and to introduce solutions addressing these sentiments if they are inconsistent with the current medical knowledge.

\section{Study Limitations}

The current study contains a few limitations resulting, eg, from the way the responses were acquired. Although the study group was intended to comprise mothers of children below 18 years of age, the authors were not able to verify the authenticity of the information provided by the survey 
participants because the questionnaire potentially, without the authors' consent, could be forwarded to individuals other than members of groups associating mothers. Given the fact that the issue of immunisation nowadays raises controversies, we cannot rule out the possibility that the rates are excessively high or low due to the survey participants' prejudices. The reliability of the findings may also have been affected by the fact that the timing of the mothers' responses frequently was much later than the timing of their decision whether or not to immunise their children, hence the findings may reflect their current perceptions related to the issue rather than their opinions at the time of the relevant decision. Moreover, even if the mother replied that she did or did not vaccinate her child, we cannot verify the actual immunisation status, to provide evidence for this claim.

\section{Acknowledgments}

The authors wish to thank the Rector of the University of Rzeszów Sylwester Czopek responsible for funding a research project under a grant Students' Scientific UR.

\section{Disclosure}

The authors report no conflicts of interest in this work.

\section{References}

1. Czarkowski MP, Kondej B, Staszewska-Jakubik E, Cieleba E. Vaccinations in Poland in 2016. National Institute of Public HealthNational Institute of Hygiene-Department of Epidemiology and Chief Sanitary Inspectorate-Department for Communicable Disease and Infection Prevention and Control; 2017. [cited 16 May 2020]. Available from: http://wwwold.pzh.gov.pl/oldpage/epimeld/2016/Sz_ 2016.pdf. Accessed July 1, 2021.

2. Poles' views about the obligation to vaccinate children. Public Opinion Research Center. Research report no. 100/2017. Warsaw: CBOS; August 2017.

3. Vaccine misinformation and social media: people exposed to vaccine content on social media more likely misinformed than those exposed to it on traditional media. Annenberg Public Policy Center of the University of Pennsylvania. ScienceDaily; [cited 17 May 2020]. Available from: www.sciencedaily.com/releases/2020/02/ 200217163004.htm. Accessed July 1, 2021.

International Journal of General Medicine

\section{Publish your work in this journal}

The International Journal of General Medicine is an international, peer-reviewed open-access journal that focuses on general and internal medicine, pathogenesis, epidemiology, diagnosis, monitoring and treatment protocols. The journal is characterized by the rapid reporting of reviews, original research and clinical studies
4. Stecula DA, Kuru O, Jamieson KH. How trust in experts and media use affect acceptance of common anti-vaccination claims. $H K S$ Misinform Rev. 2020;1:1-11.

5. Pisaniak P, Śmietana G, Piękoś D, Ozga D.Healthcare professionals as an essential part of public immunization education. Przeglad Lekarski. 2019;76(6):374-377.

6. Hadjipanayis A, Esso D, Torso S. Vaccine confidence among parents: large scale study in eighteen European countries. Vaccine. 2020;38 (6): 1505-1512. doi:10.1016/j.vaccine.2019.11.068

7. Hofstetter MA, Robinson DJ, Lepere K, Cunningham M, Etsekson N, Opel JD. "Clinician-parent discussions about influenza vaccination of children and their association with vaccine acceptance". Vaccine. 2017;35(20):2709-2715. doi:10.1016/j.vaccine.2017.03.077

8. Zarobkiewicz MK, Zimecka A, Zuzak T, Cieślak D, Roliński J, Grywalska E. Vaccination among Polish university students. Knowledge, beliefs and anti-vaccination attitudes. Hum Vaccin Immunother. 2017;13(11):2654-2658. doi:10.1080/ 21645515.2017.1365994

9. Wang E, Baras Y, Buttenheimb AM. Everybody just wants to do what's best for their child: understanding how pro-vaccine parents can support a culture of vaccine hesitancy Vaccine. Vaccine. 2015;33 (48):6703-6709. doi:10.1016/j.vaccine.2015.10.090

10. Where can I find updated information on the composition of vaccines? National Institute of Public Health. [cited 16 May 2020]. Available from: https://szczepienia.pzh.gov.pl/faq/gdzie-moznaznalezc-aktualne-informacje-dotyczace-skladu-szczepionek-w-tymwszystkich-substancji-pomocniczych-rowniez-tych-wystepujacych -w-sladowych-ilosciach/. Accessed July 1, 2021. [in Polish.]

11. What are adverse vaccine reactions? National Institute of Public Health; [cited 23 February 2020]. Available from: https://szczepie nia.pzh.gov.pl/wszystko-o-szczepieniach/co-to-sa-niepozadaneodczyny-poszczepienne/. Accessed July 1, 2021. [in Polish].

12. Anti-vaccination movements are based on psychological mechanisms; 26 December 2019 [Cited 24 September 2020]. Available from: https://forsal.pl/artykuly/1446060, ruchyantyszczepionkowe-bazuja-na-mechanizmach-psychologicznych-otokilka-z-nich.html. [in Polish].

13. Karwowska A. Kindergartens and nurseries only for vaccinated children; [cited 26 May 2020]. Available from: http://wyborcza.pl/ TylkoZdrowie/7,137474,24023922,przedszkola-i-zlobki-tylko-dlazaszczepionych.html. [in Polish].

14. Vaccinations: parents ask, experts answer. Inoculate with knowledge; [Cited 17 April 2020] Available from: http://zaszczepsiewiedza.pl/ aktualnosci/szczepienia-rodzice-pytaja-eksperci-odpowiadaja/. Accessed July 1, 2021. [in Polish].

15. Pisaniak P, Konarska M, Tarczon A, et al. Mothers' opinions on vaccinations and penal responsibility for vaccination avoidance in nine selected European countries: findings from a cross-sectional survey. Risk Manag Healthc Policy. 2021;14:1241-1254. doi:10.2147/RMHP.S283796 